\title{
The dynamics of power and resistance in police interview discourse
}

\author{
ART I C L E 739 \\ Discourse \& Society \\ Copyright (c) 2006 SAGE Publications \\ (London, Thousand Oaks, CA and New Delhi) \\ http://das.sagepub.com \\ Vol 17(6): 739-759 \\ $10.1177 / 0957926506068430$ \\ KATE HAWORTH \\ UNIVERSITY OF NOTTINGHAM
}

A B S T R AC T. This is a study of police interviewing using an integrated approach, drawing on conversation analysis (CA), critical discourse analysis (CDA) and pragmatics. The study focuses on the balance of power and control, finding that in particular the institutional status of the participants, the discursive roles assigned to them by the context, and their relative knowledge, are significant factors affecting the dynamics of the discourse. Four discursive features are identified as particularly significant, and a detailed analysis of the complex interplay of these features shows that power and control are constantly under negotiation, and are always open to challenge and resistance. Further it is shown that discursive dominance is not necessarily advantageous to participants, due to the specific goals and purposes of the police interview context. A wider consideration of the context illustrates the contribution that linguistics can make to the use of police interview data as evidence in the UK criminal justice system.

K E Y WO R D S: conversation analysis, critical discourse analysis, forensic linguistics, institutional discourse, police interview, power

\section{Introduction}

This study involves an analysis of power and control in an English police interview with a murder suspect. The data used here is of particular interest as it involves a high-profile and highly unusual interviewee: Dr Harold Shipman. Shipman was convicted in January 2000 of the murder of 15 of his patients, and a subsequent inquiry found that he murdered an estimated 260 people over a 27 -year period. He evaded any suspicion until the death of Mrs Kathleen Grundy in 1998 and the appearance of a clumsily forged will naming him as the sole beneficiary. The interview used in this study took place at the early stages of the investigation, and concerns the death of Mrs Grundy. Shipman maintained his innocence throughout the interview process and subsequent trial, despite overwhelming evidence of his guilt.

The interview format has long been recognized as being of special interest as a form of discourse with built-in asymmetry between participants in terms of prescribed discursive roles (see for example Clayman, 1992, 1993; Fowler et al., 1979: 63-80; Greatbatch, 1986, 1988, 1992). However, relatively little research has been undertaken on police interview discourse. Yet police interviews have an extremely significant practical function with far-reaching consequences. They may well constitute one of the most important conversations of an interviewee's life. They therefore represent a particularly interesting and important area of linguistic study. In police interviews with suspects the role of each participant is clearly defined and restrained. Yet these roles are very unequal, especially in terms of the distribution of power and control. In addition to the asymmetric dynamic created by the ascribed roles of questioner and responder, the police have a considerable degree of direct power over the interviewee, controlling the setting in which the interview takes place and having the capability to make vital decisions about the interviewee's liberty and future based on the outcome.

Nevertheless, interviewees still have control over what they say, and that is the most crucial part of the interaction. The whole point of the interview process is for the interviewer to gain information from the interviewee. Thus although the police interviewer is ostensibly in control of the situation, the outcome of the interview is very much in the hands (or rather words) of the suspect interviewee.

The question of power and control is therefore an important aspect of police interview discourse. The interview material examined here is particularly promising for a study of this kind. Here we have a classic 'institutional discourse' context in that a representative of an institution (the police) is conducting a conversation as part of his institutional role with someone who is not part of that institution. But that person is a member of a different institution, and his presence in this context (as a suspect) is tied very closely to that institutional role (i.e. as a doctor being questioned about his patients). What this study reveals is how the dynamics of the discourse operate in these unusual but fascinating circumstances.

As mentioned above, surprisingly little research has been undertaken on police interview discourse. Of what there is, much uses data from legal systems other than the UK's (e.g. Heydon, 2005 - Australia; Shuy, 1998 USA; Watson, 1990 - USA). The different legal framework underpinning the context, and hence the (subtly) different goals of the participants, make direct comparisons with UK police interview data problematic. For 
example, Linell and Jönsson note that in Sweden (in 1991) '[t]he major objective of the policeman is to provide a written report, which is supposed to sum up the relevant and important aspects of the criminal actions and their background' (1991: 79). This written report is not a feature of current UK police interview practice, and thus participants in the UK context are orientating to different tasks and goals.

Further, much of the work carried out on UK data has used interviews conducted before the introduction of the Police and Criminal Evidence Act 1984, which radically altered police interview procedure by imposing the requirement for audio recording (e.g. Coulthard, 1996, 2002; Thornborrow, 2002). The relevance of such research to current studies is therefore problematic for the same reasons.

Of course, for a purely CA analysis such differences may not be of great significance. However, those with a special interest in legal contexts, particularly within the growing field of forensic linguistics, cannot afford to ignore such factors. There is thus a significant gap to be filled in terms of research conducted on current UK police interview data.

A further aspect which has yet to be considered is the use to which police interview data is put throughout the UK criminal justice system. In order to fully understand the nature of the interaction, it is vital to view the police interview not as an event which occurs in isolation, but as an intrinsic part of a much wider process. It is not only a means of evidence gathering, but also becomes a piece of evidence in itself submitted to the court at trial. The consequences of this will be considered here, along with a wider discussion of the contribution that linguistics can make to this aspect of the UK judicial process.

\section{Approaches}

\subsection{INSTITUTIONAL DISCOURSE}

Defining 'institutional discourse' is not a straightforward matter. On an intuitive, common sense level there seems no difficulty in describing interactions between doctors and patients or police and public as 'institutional', but it is less easy to pin down a definition of exactly how these differ from other forms of interaction. It is also extremely difficult to draw a meaningful boundary between institutional and non-institutional discourse, not least because both can occur within a single interaction. For the purposes of this study, I give cautious endorsement to the following description:

... institutional discourse can perhaps be best described as a form of interaction in which the relationship between a participant's current institutional role (that is, interviewer, caller to a phone-in programme or school teacher) and their current discursive role (for example, questioner, answerer or opinion giver) emerges as a local phenomenon which shapes the organisation and trajectory of the talk. In other words, what people do in institutional encounters is produced, overall, as a result of this interplay between their interactional and discursive role and their institutional identity and status.

(Thornborrow, 2002: 5)

This interplay between the discursive and institutional roles of participants is considered in the present study to be a particularly significant factor.

\subsection{AN INTEGRATED APPROACH TO DA}

A multi-method discourse analytic approach is taken in this study, combining Conversation Analysis (CA), Critical Discourse Analysis (CDA) and pragmatics. In particular I take CA's approach to data collection and analysis, using naturally occurring data and undertaking a close analysis of detailed transcripts. The analytical emphasis is on the micro features of the interaction and its sequential organization. However, the identification of power and control as potentially significant factors in the chosen interaction owes much to CDA, which allows a wider consideration of the significance of the institutional context and the social identities and status of the participants.

It may seem that CA, with its emphasis only on features which are demonstrably relevant to and oriented to by participants in an interaction, and CDA, which by contrast gives automatic pre-eminence to the relevance of the wider social context, are mutually incompatible. There has been much debate on the relationship between the two (e.g. Billig and Schegloff, 1999; Schegloff, 1997) which I will not reproduce here. The approach taken here recognizes the methodological strengths and weaknesses of each. It thus aims to avoid the problem Fairclough identifies with CA of giving 'a rather implausible image . . of conversation as a skilled social practice existing in a social vacuum' (1989: 12), while also avoiding the tendency of CDA to assume that power and status are pre-ordained and pre-allocated in a given context.

This approach thus recognizes the importance of including both micro and macro features in a sound analysis of power in discourse. It combines the analytical strengths of CA with the critical social stance of CDA, without sacrificing the pre-eminent focus on the data itself. 


\subsection{POWER}

Again, I shall not attempt to reproduce here the arguments over the definition of power. This article adopts Thornborrow's position in relation to power in discourse, which she describes as something which is constantly negotiated and constructed in the interaction between participants. She summarises her position as follows: ... the approach I adopt to power . . . is to see it as a contextually sensitive phenomenon, as a set of resources and actions which are available to speakers and which can be used more or less successfully depending on who the speakers are and what kind of speech situation they are in. From this perspective, power is accomplished in discourse both on a structural level, through the turn and type of space speakers are given or can get access to, and, on an interactional level, through what they can effectively accomplish in that space.

(Thornborrow, 2002: 8)

\section{Methodology}

\subsection{THE DATA}

The data analysed in this study represent one of several interviews conducted by the police with Dr Shipman. In a highly unusual move the police released the tapes of two of these interviews to the public. I obtained the audio files used in this analysis from the BBC News website archives. I It should be noted that (despite the claim made on the website) these appear to have been edited. However, they are almost certainly the versions agreed by the Prosecution and presented as evidence at Shipman's trial.

\subsection{ANALYTICAL FRAMEWORK}

My analysis reveals four features of particular significance in terms of the dynamics of power and control in this interview. These are: (1) topic; (2) question type; (3) the question-answer sequence; and (4) allusions to institutional status.

\subsubsection{Topic}

The significance of topic as a factor in the distribution of power and control in an interview setting is highlighted by Greatbatch in his study of news interviews. He comments that:

... news interviewers are effectively afforded sole rights to manage the organization of topics. For, in so far as they restrict themselves to answering, interviewees are obviously limited to dealing with the topical agendas which interviewers' questions establish for their turns and, as such, in contrast to interviewers, are not able to shift from one topic or topical line to another.

(Greatbach, 1986: 441)

Thus it is expected that the person in the role of interviewer will set the topical agenda, leaving the interviewee in a restricted position discursively.

\subsubsection{Question type}

In considering the syntactic form and function of the questions used in these data, I follow the approach of Harris in her analysis of questions as a mode of control in magistrates' courts (1984). She classifies questions by 'the nature of the responses requested' (p. 13). She found that the majority of questions used in the court require a minimal response, leading her to conclude that 'the asking of questions becomes a powerful means of controlling the discourse' (p. 14).

However, the specific classifications used by Harris are not always appropriate here, possibly due to the different context. To give an example from my data, 'do you have any comment to make about that' is a 'polar interrogative', classified by Harris as requesting 'only a minimal response' (p. 13). But this is clearly a very open as opposed to restrictive request. I will therefore not follow Harris's classification system in full, but will adopt the general approach of classifying questions according to whether they are restrictive or open in the responses they request.

In the same study Harris goes on to consider the 'functions of questions in context' (pp. 18-22). In the particular context she observes, namely a specific type of hearing about financial arrears, she identifies two major functions: information and accusation (p. 19). She also states that:

... requests for confirmation can apply either to questions relating to information or to accusations. Hence I have not considered confirmation as a separate function, as what is confirmed is always either an information question or an accusation.

(Harris, 1984: 21)

But in the rather less limited context I am examining, there is a difference between a question which is information-seeking and one which is confirmation-seeking, particularly in terms of the comparative level of 
knowledge it reveals about the person asking the question. I therefore identify the function of questions in terms of whether they are: (1) information-seeking; (2) confirmation-seeking; (3) explanation-seeking; or (4) accusatory.

\subsubsection{Question-answer sequence}

This considers the basic expected sequence of the interviewer's turns as questions and the interviewee's as answers. Just as with topic, the role of questioner gives a large degree of power to that participant, allowing them not only to set what is an acceptable next turn from the other participant, but further to sanction the responder if their response is not deemed acceptable. It is open to the responder to comply with the expected sequence and co-operate with the interviewer, or to resist.

\subsubsection{Institutional status}

The fourth feature refers to participants' identification of themselves and each other in terms of their professional role. This is manifest in this interview in two ways: first, in appeals by participants to their own institutional status and, second, in attempts to undermine the other's status.

I found that patterns of these four features emerge through the sequence of the interview, with corresponding shifts in power and control as the interaction unfolds. These shifts occur precisely at the points at which the topic changes. I shall therefore work through the topical sequence of the interview, showing how the dynamics change and how these changes are achieved discursively through the interrelation and exploitation of these key features.

\section{Results}

\subsection{OPENING SEQUENCE}

We have already noted that there is an expectation that the police interviewer $(\mathrm{P})_{2}$ will control the topical agenda. Yet right at the start we see something different. $\mathrm{P}$ goes through the formulaic opening to the police interview, namely the mandatory caution, and then starts to set up his agenda for this interaction. But as soon as $\mathrm{P}$ has completed enough of his utterance to make it clear that he is about to introduce a topic, Shipman (S) interrupts:

P: $\quad$. . . there's one or two points we'd like to pick up [on from]

S: $\quad$ [errr] can I clarify something first.

P: yeah

S: I've had the chance to mull over the questioning this morning, (.) and perhaps I've made clear what ha- happened when Mrs (.) Grundy asked me to witness the will. . . .

$\mathrm{P}$ defers to $\mathrm{S}$ and lets him continue, thus abandoning his own topic introduction. $\mathrm{S}$ then introduces his own topic instead. Bearing in mind the expected balance of power in favour of $\mathrm{P}$ in terms of setting the topical agenda of the interview, this marks a significant breach of that order right at the start of the interaction. This also represents a breach of the expected question-answer sequence of the interview, in that here S takes a turn which is not a response to a question from P. Yet, disorderly as this is, it is achieved in a way that acknowledges that a breach is taking place and thus orients to the expected turn-taking sequence. This is a feature identified by Greatbatch in news interviews:

In initiating such departures, IEs often start out by producing objects that display an orientation to the fact that they are talking out of turn ... These objects take the form of 'requests for permission to speak' (Schegloff 1980) and fall into two broad groups: those which are produced as genuine requests requiring responses from IRs and those which, by contrast, are produced as 'token' requests (i.e., as first components in projected turns)

(Greatbatch, 1988: 419)

Although this sequence still represents a challenge to the questioner-responder roles assigned to the participants by the context, the effect of the 'genuine' request is to mitigate that challenge and acknowledge the overall control of $\mathrm{P}$. P lets $\mathrm{S}$ continue with a fairly long turn, not intervening despite several pauses, and even encouraging him with back-channelling. By so doing he effectively hands $\mathrm{S}$ even more discursive freedom. But this introduces a highly significant feature of the police interview context: the overall aim is to get an 
interviewee to talk. Thus $\mathrm{P}$ is constrained by the institutional context into allowing $\mathrm{S}$ to talk 'out of turn' here. In S's continuing turn there is also an element of implied criticism of P's role as questioner:

S: . . that obviously didn't come out in this morning's interview, (.) and now

I've clarified the situation. $(21-2)$

This is a challenge which P does not let pass:

P: you were asked a question (.) this morning you had the opportunity to give $(23-4)$ that answer this morning. is there any reason why you didn't?

Several features show how $\mathrm{P}$ is attempting to reassert his discursive position here. He directly addresses the implication that there was an omission in his earlier questioning: 'you were asked a question this morning' (23). Further, he clearly orients to the expected format of his turns as questions and S's as answers, by directly referring to S's turn as an 'answer' (24) despite the fact that, as noted, it does not occur as a response to a question. He thus reasserts the expected order and dismisses S's challenge. We can see right from the start, then, that the question of control is a crucial one in this interaction, and that it is certainly not a straightforward matter of the participant with the role of questioner having an unassailable position of power. $\mathrm{S}$ has right away shown his unwillingness to comply with the restrictions imposed upon him by his role as responder, and has also displayed his ability to challenge P. P, meanwhile, has to continually assert his power in order to maintain it.

\subsection{MRS GRUNDY'S MEDICAL RECORDS}

P now gets to introduce the first main topic, namely Mrs Grundy's medical records. P makes it explicitly clear that he is unilaterally changing the topic:

P: $\quad$ OK (-) I want to go back to the (.) computer (.) medical records ...

Throughout this sequence S picks up P's topic. However, that is not to say that his responses are straightforwardly co-operative. S's first response in this section simply does not answer P's question:

P: the entry for (.) Mrs Grundy's visit on the 9th of June, (.) will

you tell me why (.) there's no reference there (.) to you taking any blood

from her.

$(-)$

$\mathrm{S}: \rightarrow$ normally (all) the blood results came back two days later.

P: no but (can you tell me) why there's no (.) mention on that date.

S: I cannot give you an explanation.

$(35-41)$

His answer does give the surface appearance of conformity, in that taken on its own it sounds like a legitimate and helpful answer - but not to the question asked. This is therefore a subtle form of subversion rather than a blatant challenge. The illusion of compliance is at least worth maintaining. P recognizes this challenge and sanctions S, repeating his question (40). Failure to answer for a second time would have been a blatant challenge, and sure enough this time $\mathrm{S}$ replies. But although $\mathrm{P}$ maintains some control here, this demonstrates that his grip on it is by no means firm. The chosen topic allows $\mathrm{S}$ to display his institutional status:

P: $\quad$. . it doesn't actually say you'd taken a

blood sample from her.

S: $\quad$ errm (-) it's not the custom of most general practitioners to write, (.) "I

have taken a blood sample which would consist of this this and this" most general practitioners just write down what the blood test is that they're doing.

$(76-81)$

This is another interesting evasive tactic, in that $\mathrm{S}$ does not address what he actually did, but instead refers to the 'custom' of his peers: he implies he has merely followed standard practice for his profession. He thus uses his professional status as a shield, shifting the focus of blame onto the institution to which he belongs, instead of on himself as an individual member. Further, due to the subject matter belonging entirely to S's medical domain, $\mathrm{P}$ has no choice but to defer to S's knowledge and professional status at this point, leaving himself in a weak position discursively. Even the use of restrictive question-types fails to assist him: 
P: do regulations not state that er you should record (.) erm (.) taking blood samples, or (.) making notes of

(.)

S: regulations state that you should make records at every attendance (.) and I think you will agree that there is a record there for the day that I visited, (.) and also (.) that I (.) took blood.

(96-101)

P starts with a strong, conducive question form, namely a declarative with a negative interrogative frame (Harris, 1984: 17), which strongly encourages the recipient to agree with the statement contained within it. But he falters: his lack of mastery of the subject matter is reflected in the pauses and hesitations, and in the incompleteness of his turn. (There are many possible medical procedures which $\mathrm{P}$ could have named to complete this utterance, but despite a pause he does not come up with any.) This gives the distinct impression that $\mathrm{P}$ does not in fact know what the regulations state. This allows $\mathrm{S}$ to capitalize on his stronger position and take up an informing role, with the power to impart knowledge which he knows only he has and so which can't be challenged.

Further, in his response $\mathrm{S}$ subverts their ascribed roles once again, getting $\mathrm{P}$ to agree with his statement rather than the other way round ('I think you will agree that. . ': 100). Even more significantly, he manages to imply that $\mathrm{P}$ agrees with him that there is a record of him taking blood, which is one of the key points that $\mathrm{P}$ has been disputing in this sequence (see lines 35-41 quoted above). At this point of weakness $\mathrm{P}$ chooses not to challenge $\mathrm{S}$, but to change the topic.

\subsection{THE AGEING SURVEY}

Although $\mathrm{P}$ gets to introduce the topic once again, it is another about which $\mathrm{S}$ has fairly exclusive knowledge, namely a national survey on ageing in which his surgery was participating. And as with the previous topic $S$ picks it up, again using it to emphasize his institutional status:

P: . . . it can take over a period of time can it to do these different tests that you have to do, (.) or wish to do, (.) because with Mrs Grundy's case it was 98 .

(.)

S: if you're (talking back) to the 95 study we (?) er produced a base line. (.) the idea was that we (.) saw people at home, checked the lighting, heating, (.) whether they were getting the right amount of pension, (.) and so on. (.) the medical part of it was (-) well of secondary importance ... (148-55)

Here S portrays GPs as institutional authority figures, who have the right (or even a duty) to monitor the personal affairs of others. This can be seen as an attempt to align GPs as sharing the same social status as the police, and hence claiming equal standing between $\mathrm{S}$ and $\mathrm{P}$ (directly countering the inequality of their current roles). And further, $\mathrm{S}$ exploits the reputation of medicine as a caring profession (implicitly countering the notion that he would harm his patients).

Although this is another section where P has to defer to S's knowledge, here he moves away from the open questions of the previous section. All eight of the questions in this sequence are restrictive. This can be interpreted as an attempt to pin $\mathrm{S}$ down to straight answers, but this is not in fact the result, as can be seen from the exchange just quoted. (The question, 'it can take over a period of time can it', remains unanswered.) Once again we see that the question function (information-seeking) appears more significant than its form in terms of exercising control.

\subsection{DANGEROUS DRUGS}

There now follows a shorter sequence where P asks general questions about S's storage of and access to drugs. There is no element of accusation in any of the questions, nor do they seek an explanation from $\mathrm{S}$, but in a clear orientation to the institutional context $\mathrm{S}$ frequently responds as if there had been:

P: 'kay (.) erm (.) where d'you (.) access dangerous drugs (.) for (.) say the treatment say of terminally (.) ill patients

S: I would issue a prescription ... a and deliver the drug (.) directly to the

$\rightarrow$ house, (.) and that's the only time I would touch them. ...

P: $\quad$ mhm (-) what happens say (.) if (-) one of your patients (.) dies from a terminal illness, you're aware that they have (.) whatever it is the [dangerous drugs what happens (.)] to those dru[gs] 
In fact all the questions in this sequence are purely information-seeking and fairly open, with no follow-up to the information received. This seems a rather ineffective discursive strategy, and indeed marks this as a slightly unusual section of the interview.

\subsection{THE FORGED WILL}

The balance of power between P and S takes a noticeable turn with P's introduction of the topic of Mrs Grundy's will. Here P presents cogent evidence which links S to its forgery. In contrast to the previous medical topics, this is very much more on P's home ground, involving police evidence and forensic investigation. In stark contrast with the previous sections, throughout the 'discussion' of the will $\mathrm{S}$ does not in fact pick up this topic at all. He makes minimal responses to P's questions, for example: 'yes'; 'no'; 'none'; and explicitly 'no, I've got no comment to make'. Yet despite this, P continues with the topic regardless. This allows him to dominate this section of the interaction.

A closer analysis of the sequence shows how $\mathrm{P}$ maintains his dominance. First of all his turns here include a large number of declarative statements, putting $\mathrm{P}$ into the stronger role of information-giver, as opposed to information-seeker as before. $\mathrm{P}$ controls the knowledge here, not $\mathrm{S}$. He explicitly draws attention to this:

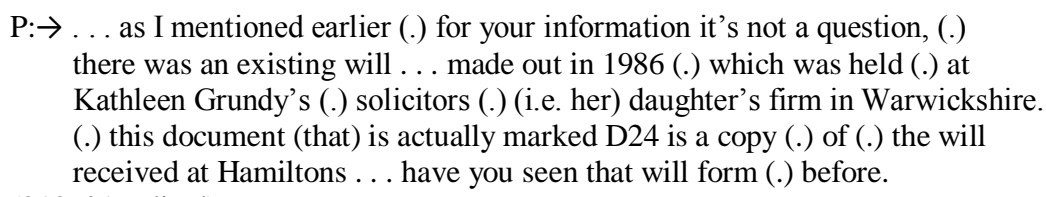

A significant number of $\mathrm{P}$ 's turns are now used to seek an explanation from $\mathrm{S}$ about the information which $\mathrm{P}$ is imparting. (Five out of 15 questions in this section are explanation-seeking, compared with only three in the entire interview thus far.) It must be noted that explanation-seeking questions are by their nature open. But it must also be noted that they clearly exercise a significant degree of power and control over interviewees, generally requiring them to justify themselves and/or their actions. This highlights once again that the distinction between open and restrictive questions is not necessarily an appropriate or valid indicator of the power dynamics in this context.

Indeed P's explanation-seeking turns largely succeed in eliciting straight answers from S, with no evasive tactics:

P: $\quad$ the letters (.) and will (.) are all typed (.) on your (.) Brother typewriter. (-) can you account for that

S: no?

$(-)$

P: $\quad$ the letter ... was clearly sent (.) after (.) Mrs Grundy's death (.) can you account for that doctor.

S: I cannot.

(237-44)

These answers represent a distinct weakening of S's position in that a request for an explanation is made, but the preferred response, i.e. an explanation, is not provided. This cannot be interpreted as an act of resistance as this is precisely the answer $\mathrm{P}$ wants in order to strengthen his case against $\mathrm{S}$. The appropriate way to counter the power of P's position would have been to provide a valid explanation and thus weaken P's case.

But S does not allow P's dominance to go completely unchallenged. Despite the strength of the evidence being presented against him, S still carries out several acts of resistance. And it is noticeable that each of these follows a 'weaker' question type from P. The first occurs straight after the sequence of explanation-seeking turns just quoted (237-44). $\mathrm{P}$ then asks a question which again puts him back in the information-seeking role:

P: $\quad$ who would have had access to your typewriter (.) after Mrs Grundy’s death

(-)

S: the question is when was it returned to the surgery. (.) and that I don't know. 
This 'reformulation of the question' (Clayman, 1993) is another way for S to avoid answering P's question, while still giving the impression that he is complying. It also gives $\mathrm{S}$ a degree of power over P's previous turn. As Clayman notes, '[a]s paraphrases, reformulations do not merely repeat the preceding question in a literal, word-for-word manner; they recast the prior in a way that alters its character' (1993: 163). What is more, it also allows S to usurp P's role as questioner: S simply sets his own question and answers that instead.

Another example occurs towards the end of this section. Here P moves to direct accusation:

P: $\quad$ can I put it directly to you doctor (.) that you (.) forged (.) you have

produced (.) the letters and this will (.) on your typewriter in the hope of

$(270-2)$

benefitting from Mrs Grundy's estate.

Yet this is a less strong formulation than it might have been, in that he mitigates his 'direct' statement with the rather cautious and polite interrogative request 'can I put it directly to you. ..' (270). This is immediately exploited in S's next turn:

S: is that a question or a statement.

This is an incredible response in the circumstances. It represents a strong challenge to P's role as questioner and of course it also takes the form of a question itself. But $\mathrm{S}$ has just been directly accused of forgery and, by implication, murder, for the first time in this interview, giving him the first opportunity to rebut this accusation. The fact that he does not instantly produce a denial (the expected 'second pair part' to an accusation, Schegloff and Sacks, 1973: 296) is certainly not a good tactical move on his part. His desire to challenge P appears to have overridden what one might have expected to be a paramount desire to assert his innocence. Thus S's attempts here to resist the power and control of $\mathrm{P}$ can in fact be seen to result in a weakening of S's own position.

\subsection{CAUSE OF DEATH}

The topic of the cause of death represents something of a crossover between the legal and medical domain, involving forensic evidence, but of a medical nature. It is therefore open to either $\mathrm{P}$ or $\mathrm{S}$ to dominate this section by steering it in the direction of their particular expertise. $\mathrm{P}$ begins by revealing that a forensic examination has detected fatal levels of morphine in Mrs Grundy's body, but then hands the initiative to S by using an open explanation-seeking question: 'do you have any comment to make about that' (287). This worked in P's favour on the topic of the will, as there was little scope for a plausible explanation from S. But here it hands the floor completely to $\mathrm{S}$, allowing him to take the topic in the direction of his choosing.

He chooses to discuss Mrs Grundy's previous medical history, a subject over which he has sole knowledge as it is based purely on his own medical notes. He thus gets to speak at length here on his own version of events, namely that Mrs Grundy was a drug user and accidentally overdosed. Indeed there are several long pauses where $\mathrm{P}$ could have intervened, but instead he simply allows $\mathrm{S}$ to continue. In fact $\mathrm{P}$ effectively only gets to ask one question in this whole 77-line sequence. He is twice interrupted by $\mathrm{S}$ before being able to complete subsequent turns. And, significantly, for several turns $\mathrm{P}$ is forced into the role of responder:

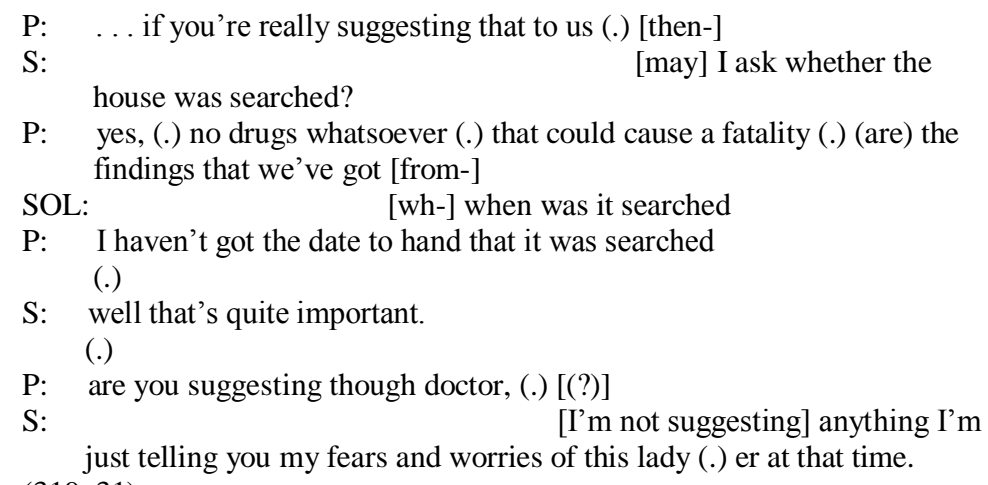
$(319-31)$

This is another clear challenge to $\mathrm{P}$, with S not only usurping P's position as questioner, but also implicitly criticizing his institutional status as an investigator. Yet $\mathrm{S}$ still orients to the expected format which he is breaching with a 'request for permission to speak' ('may I ask. . ': 320), but this time the request is clearly 'token' as he continues without waiting for permission (Greatbatch, 1988: 419). Thus $\mathrm{S}$ has by this stage moved to a much more challenging line of resistance than at the start of this interview. 
With regard to the reversal of questioner-responder roles, Harris identifies such 'counter-questions' as a key mode of resistance to power and control (1989: 140-6). Thornborrow also observes this tactic being used in a police interview. She comments that:

... it is the institutional roles occupied by the participants ... that largely determine whether or not the outcome of these actions is successful or not. [The police officer] has no institutional obligation to participate as an 'answerer', and resists taking up this position when [the interviewee] puts him in it discursively ... When a participant is placed discursively in a turn position that in some way conflicts with their institutional role, we can observe a degree of disruption to expected norms of interaction while the police interviewers re-establish their more powerful positions in the talk.

(Thornborrow, 2002: 53)

Yet the re-establishment of the police officer's power is not such a straightforward matter here. $\mathrm{P}$ does take up the role of 'answerer' (322-5), and when he subsequently tries to break out of this role and re-establish himself as questioner (329) he is interrupted by $\mathrm{S}$ and prevented from finishing his turn (330). This is indeed disruption, but it comes from S continuing his resistance and not from P reasserting himself. Control of this interaction is still very much under negotiation here.

\subsection{CLOSING SEQUENCE}

The final section of the interview takes the form of a summary, with every topic addressed briefly again by P. Fascinatingly, to a large extent we also see the whole discursive pattern of the interview reproduced in microcosm.

A key difference is that here all the questions are restrictive, and all are to some degree accusatory. P takes the key point elicited from each topic and directly challenges $\mathrm{S}$ with it. But the responses and the tactics used by $\mathrm{S}$ closely mirror the pattern established in the main body of the interview. First of all P mentions the ageing survey, which as noted above is a strong topic for $\mathrm{S}$. And sure enough, here $\mathrm{S}$ interrupts $\mathrm{P}$ before he can formulate a question, corrects $\mathrm{P}$, and heavily emphasizes his own privileged, caring institutional status:

P: ...you (.) tell us you're involved in some ageing survey, [?]

S: $\quad$ [I'm not] telling you (.) I'm involved in an ageing survey.

(.) I'm involv- involved with the care of elderly patients as recommended

by the government (.) in the health of the nation (.) which involves

looking after patients

(359-64)

$\mathrm{P}$ then changes to a different topic, namely the cause of death. Now P makes a direct accusation of murder. This time he uses the stronger declarative form, rather than the weaker interrogative frame which caused him so much trouble in the discussion of the will:

P: I suggest to you (.) that you have injected (.) Mrs Grundy with a fatal (365-6) overdose of morphine and brought about her death!

But S's response here is also stronger. He issues an immediate denial, and even adds a note of criticism of P's professional role:

S: no, (.) and you tell me that (.) people in Hyde don't have access to drugs $(367-8)$

(.) I think you should talk to your drug squad.

P's discursive tactics fail to gain advantage over S once again. P now returns to the one topic that has previously allowed him to dominate $\mathrm{S}$, namely the forged will. It is interesting to note that in the rest of this sequence $\mathrm{P}$ only asks one question per topic, but here on the subject of the will he asks four. And each time, S makes no response at all. This once again reflects the dominance $\mathrm{P}$ achieved with this topic earlier in the interview. But then P moves on to a topic which is much more comfortable for S: his patient's medical history. S does now respond, and he uses tactics which have served him well in the past. First he gives an answer which is apparently cooperative but on closer inspection does not answer the question; then he interrupts P's next turn 
before he can complete it. He then emphasizes his institutional and professional status, before finally committing a further act of subversion by guessing the question $\mathrm{P}$ was intending to ask and answering that instead:

S: $\quad$... we were just looking after our elderly patients in the way we do, (-) so $(394-5)$

no I don't think it was peculiar not to ask for a post mortem.

This 'pre-empting of the question' is a very direct way of challenging P's role as interviewer. S not only effectively selects his own question, but also indicates that he can see P's 'hidden agenda' (Drew and Heritage, 1992: 50); that he knows in advance what $\mathrm{P}$ is going to ask and why, and is thus more than a match for the painfully obvious and inadequate police questioning. There is a long pause at this point, after which $\mathrm{P}$ appears to move towards closing the interview. But then, instead of letting it end with his last question having been successfully blocked by $\mathrm{S}$, he asks one more:

$\mathrm{P}:$

... I will ask you a

question. (.) er re the drugs, (.) you don't keep any drugs in er (.) your surgery, (.) is that correct (399-401)

This seems a rather ineffective note to end on, not least because it does not involve the element of accusation contained in all the other questions in this final sequence. Instead it merely seeks confirmation of a point which $\mathrm{S}$ has already confirmed earlier in the interview. But note P's opening: 'I will ask you a question'. After all the disruption and subversion achieved by this particular interviewee, $\mathrm{P}$ here explicitly invokes the expected police interview script, where $\mathrm{P}$ asks the questions and $\mathrm{S}$ answers them. How ironic, then, that $\mathrm{P}$ leaves himself open to a correction by $S$ :

S: I don't keep any drugs (.) if you're talking about controlled drugs. . (402)

The only remaining resource left to $\mathrm{P}$ is to call an end to the interview.

\section{Discussion}

\subsection{THE INTERVIEW}

Through the above analysis several factors emerge as being of particular significance in the balance of power and control in this interview. The ascribed discursive roles of the participants are of paramount importance, providing the 'default' positions from which each participant must operate. As we have seen, these are very unequal in the resources they make available to each participant, giving $\mathrm{P}$ a considerable advantage in terms of power and control in this interaction. However, although this 'starting position' may be fixed, what each manages to achieve from there is not. In line with the asymmetrical default positions, we have seen that $\mathrm{P}$ does have overall control of the interaction, whereas $\mathrm{S}$ is generally left in the position of attempting to resist that control, rather than being able to actually seize it for himself. Yet the level of resistance he manages to achieve is quite remarkable given the circumstances. Through his constant attempts to challenge and undermine P's position, he significantly reduces the default advantage with which $\mathrm{P}$ started out.

In addition, the institutional roles of the participants have been shown to have a strong influence on the interaction. S uses his professional status to bolster his discursively weaker position and place himself on a more equal footing with P. He also constantly undermines P's status, both as investigative officer and as questioner. It is interesting to note that $\mathrm{P}$ rarely alludes to his own institutional position - but this is hardly necessary in the context. His stronger discursive role as questioner is itself a manifestation of that status.

This leads neatly onto another key feature revealed in the analysis: the significance of the institutional context. We have seen that in several places $\mathrm{S}$ is left free to talk at some length in a direction apparently not of P's choosing, effectively handing him quite a degree of discursive control. But it must be borne in mind that the overall goal of the interaction is to get $\mathrm{S}$ to talk. $\mathrm{P}$ is therefore restricted by his institutional role into conceding discursive power and control at times in order to achieve the wider goals of the interaction. Indeed there is one crucial point where $\mathrm{S}$ takes control but only to his own detriment. That is his alternative explanation for the fatal level of morphine discovered in Mrs Grundy's body. S's theory that 81-year-old Mrs Grundy was a drug abuser seems patently absurd and thus a fairly hopeless and desperate line of defence. If this is the best explanation that $\mathrm{S}$ can provide other than the fact that he murdered her, then $\mathrm{P}$ appears to have a very strong case against him. It is significant that this explanation was obtained from $\mathrm{S}$ by $\mathrm{P}$ making a very open request for comment and giving up his powerful discursive position in order to allow $\mathrm{S}$ to speak freely. Harris has stated that: 
I would argue that the data analysed here support that view. Whatever other factors are in play, ultimately control of the interaction is achieved on a turn-by-turn basis through the use of discursive strategies and techniques. Power and control can always be challenged by the use of discursive strategies, regardless of the subject matter, the status of the participants, or any other factor. However, although such challenges are indeed possible, they might not necessarily be wise in this context, and can in fact lead to a weakening of the challenger's position in the wider sense. Given the overall aim of building a case against S, it has been seen that $\mathrm{P}$ in fact gains the most when $\mathrm{S}$ does take discursive control. Thus it is just as important to know when to relinquish power and control in this context as it is to maintain it.

\subsection{THE TRIAL}

Data from this particular interview were relied on heavily by the prosecution throughout Shipman's trial. Extracts were quoted at virtually all significant points, especially during cross-examination of Shipman himself and also in the judge's summing up to the jury. Two specific points were utilized to great effect: first, Shipman's alternative explanation that Mrs Grundy was a drug user, described in the prosecution opening speech as 'perhaps the most significant thing that Dr. Shipman said to the police in interview' (Trial day 2);3 and, second, his denial that he kept dangerous drugs. It is instantly noticeable that these points both result from sections identified in my analysis as representing the least discursively strong tactics on the part of P. In particular, my analysis identified the sequence on dangerous drugs as being particularly unusual in terms of the use of solely 'weak' question types and the lack of any follow-up by P to Shipman's responses. However, as soon as the bigger picture is considered, it becomes clear that in fact the simple answer by Shipman that he did not keep dangerous drugs was one of the most crucial in terms of what it represented to the wider investigation. As revealed at trial, the police not only had the evidence of a witness who saw Shipman removing drugs after the death of a patient, they also found diamorphine at his own home. They therefore had proof that his response here was a lie. There can have been little more damning to Shipman than this.

This highlights the dangers of looking only at the immediate context of the police interview in isolation from its role throughout the entire judicial process of which it is an intrinsic component. By failing to take into account the wider goals to which the police interviewer will (consciously or not) be orientating, the researcher is likely to miss vital aspects which are clearly a key influence on the interviewer's discursive strategy.

\subsection{THE WIDER PICTURE}

Finally, I wish briefly to consider the contribution linguistics can make to enhancing the use of police interview data in the UK criminal justice system. As already noted, interview data is presented to the court as evidence at trial and often has a significant bearing on the outcome of the case. Yet through the judicial process the interview data is transformed and 'interpreted' to an extent which goes entirely unnoticed in legal circles but which is of great significance from a linguistic perspective. First, the original discourse is tape-recorded, and the quality of the recording often leaves a great deal to be desired. The tape is then transcribed by clerks within the police force. Features such as overlap, interruption and discourse markers are routinely omitted. From that point onwards, certainly in my own experience as a CPS prosecutor and trial advocate, the transcript is used almost exclusively in preference to the tape recording. When it comes to presenting the interview as evidence in court, the rather bizarre custom is for the transcript to be read out loud, with the prosecutor taking the part of the defendant and a police witness reading out the interviewer's turns. The potential distortion of the evidence through this process will be obvious to the linguist, yet is almost entirely unrecognized within the justice system.

An illustration of this occurs within the Shipman trial. As noted above, a significant aspect of the prosecution case was Shipman's response in the interview that he did not keep any dangerous drugs, alongside the fact that drugs were found when his home was searched. The response given by Shipman is directly quoted by the prosecution in cross-examination. Yet (according to the official court transcript, which of course is itself a potential source of error) there is a difference between the version used at trial and my own transcription:

Version put to Shipman by the prosecution:

، “. . . The drugs, you don't keep any drugs in your surgery, is that correct?"

Dr. Shipman: "I have given you all the drugs. Are you talking about controlled drugs?"” (Trial Day 32)

Author's version: 
Considering the importance of this point, such a difference is of real concern. A key part of the prosecution case involved establishing exactly how Shipman obtained and stored diamorphine in order to show that he had the means to carry out the murders. The version given at the trial has a quite different meaning to my own, in that there is a clear implication that Shipman has voluntarily handed over drugs to the police. But the crucial point here is that he denied ever possessing such drugs - a proven lie which significantly bolstered the prosecution case, yet which is undermined by this erroneous transcription.

I hope it is abundantly clear that linguistic research has the potential to make a significant contribution to informing and enhancing current UK practice with regard to police interview evidence, from the interview itself, through the transcription process, to the use of interview data at trial. I am currently working with several police forces with the aim of achieving exactly that.

\section{ACKNOWLEDGEMENTS}

I would like to thank Dr Louise Mullany for her invaluable comments on this paper. I also gratefully acknowledge the support of the Economic and Social Research Council.

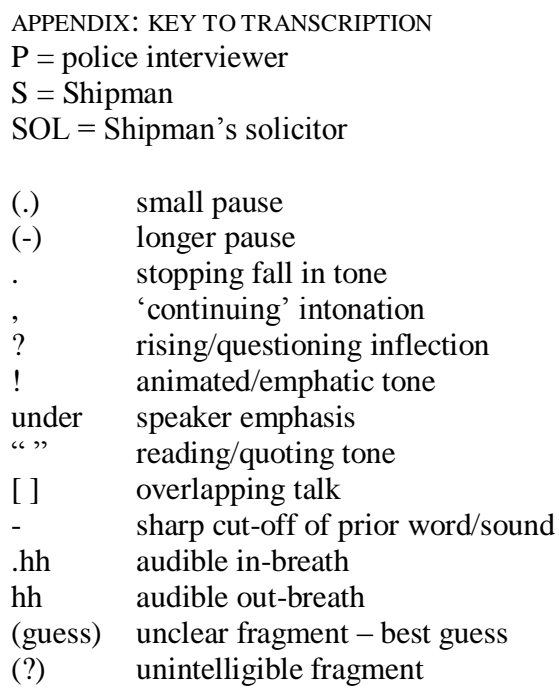

NOTES

1. http://news.bbc.co.uk/1/hi/in_depth/uk/2000/the_shipman_murders/the_shipman_files/613627.stm [accessed 20 September 2006]

2. Official transcript [accessed 20 September 2006]: http://www.the-shipmaninquiry.org.uk/trialtrans.asp

3. In fact two police interviewers participate in this interview. Unfortunately, the quality of the audio file is such that it is extremely difficult to make any reliable identification of which is speaking. However, it is clear that one officer takes the vast majority of turns. I have taken the view that this is not necessarily a significant factor in the analysis conducted here, and although I accept this is a rather unsatisfactory solution, I have designated all police turns simply to 'P'.

\section{REFERENCES}

Billig, M. and Schegloff, E.A. (1999) 'Critical Discourse Analysis and Conversation Analysis: An Exchange between Michael Billig and Emanuel A. Schegloff', Discourse \& Society 10(4): 543-82.

Clayman, S.E. (1992) 'Footing in the Achievement of Neutrality: The Case of News-Interview Discourse', in P. Drew and J. Heritage (eds) Talk at Work: Interaction in Institutional Settings, pp. 163-98. Cambridge: Cambridge University Press. Clayman, S.E. (1993) 'Reformulating the Question: A Device for Answering/Not Answering Questions in News Interviews and Press Conferences', Text 13(2): 159-88.

Coulthard, M. (1996) 'The Official Version: Audience Manipulation in Police Records of Interviews with Suspects', in C.R. Caldas-Coulthard and M. Coulthard (eds), Texts and Practices: Readings in Critical Discourse Analysis, pp. 166-78. London: Routledge.

Coulthard, M. (2002) 'Whose Voice Is It? Invented and Concealed Dialogue in Written Records of Verbal Evidence Produced by the Police', in J. Cotterill (ed.) Language in the Legal Process, pp. 19-34. Basingstoke: Palgrave. Drew, P. and Heritage, J. (eds) (1992) Talk at Work: Interaction in Institutional Settings. Cambridge: Cambridge University Press.

Fairclough, N. (1989) Language and Power. London: Longman.

Fowler, R., Hodge, R., Kress, G. and Trew, T. (1979) Language and Control. London: Routledge. Greatbatch, D. (1986) 'Aspects of Topical Organization in News Interviews: The Use of Agenda-shifting Procedures by Interviewees', Media, Culture \& Society 8(4): 441-55. 
Greatbatch, D. (1988) ‘A Turn-taking System for British News Interviews’, Language in Society 17(3): 401-30.

Greatbatch, D. (1992) 'On the Management of Disagreement between News Interviewees', in P. Drew and J. Heritage (eds)

Talk at Work: Interaction in Institutional Settings, pp. 268-301. Cambridge: Cambridge University Press.

Harris, S. (1984) 'Questions as a Mode of Control in Magistrates' Courts', International Journal of the Sociology of

Language 49: 5-27

Harris, S. (1989) 'Defendant Resistance to Power and Control in Court', in H. Coleman (ed.) Working with Language: A

Multidisciplinary Consideration of Language Use in Work Contexts, pp. 131-64. Berlin: Mouton de Gruyter.

Heydon, G. (2005) The Language of Police Interviewing: A Critical Analysis. Basingstoke: Palgrave

Linell, P. and Jönsson, L. (1991) 'Suspect Stories: Perspective-setting in an Asymmetrical Situation', in I. Markova and K.

Foppa (eds) Asymmetries in Dialogue. Hemel Hempstead: Harvester Wheatsheaf.

Schegloff, E.A. (1980) 'Preliminaries to Preliminaries: “Can I Ask You a Question?”, Sociological Inquiry 50(3-4): 104-52

Schegloff, E.A. (1997) 'Whose Text? Whose Context?', Discourse \& Society 8(2): 165-87.

Schegloff, E.A. and Sacks, H. (1973) 'Opening up Closings', Semiotica 8: 289-327.

Shuy, R.W. (1998) The Language of Confession, Interrogation, and Deception. Thousand Oaks: Sage.

Thornborrow, J. (2002) Power Talk: Language and Interaction in Institutional Discourse. Harlow: Longman.

Watson, D.R. (1990) 'Some Features of the Elicitation of Confessions in Murder Interrogations', in G. Psathas (ed.)

Interaction Competence, pp. 263-95. Lanham, MD: University Press of America.

KATE HAWORTH is a PhD student in the School of English Studies, University of Nottingham. She received a M.St. in Greek and Latin Languages and Literature from Magdalen College, Oxford in 1996 and an MA in Applied Linguistics from the University of Nottingham in 2004. She is also a barrister (now non-practising) with experience of both criminal prosecution and defence. Her current research involves an analysis of police interview discourse and its roles in the judicial process. [email: UPDATED POST PUBLICATION: k.haworth@aston.ac.uk] 